\title{
NOTAS SÔBRE ALGUNS COPÉPODOS PARASITOS DE PEIXES MARÍTIMOS DA COSTA DO ESTADO DE SÃO PAULO
}

\author{
J. de Paiva Carvalho
}

Em 1947-1948, por questões que não vêm a pêlo recordar e dada a impossibilidade de realizarmos viagens regulares de estudo ao longo do litoral do Estado de São Paulo, deliberamos pesquisar os copépodos parasíticos encontrados em peixes marítimos das costa bandeirante. Com êsse objetivo, além dos exemplares que obtivemos nas poucas excursões que realizamos, visitamos feiras e mercados de Santos e São Paulo, na expectativa de encontrar e adquirir espécimes por ventura parasitados. $\mathrm{O}$ material aqui tratado provém de 9 espécies diferentes, assim distribuidas: 8 cações, 6 bonitos comuns e 2 prejerébas, concorrendo com um representante as espécies que se seguem: baiacú, bonito rajado, sororóca, peixelua, cabrinha e pescadinha do reino. Êsse material propiciou-nos a obtenção de três espécimes que ainda não figuravam na nossa lista de ecto-parasitos e que foram incorporados às coleções do Instituto Paulista de Oceanografia. Tais aquisições, adicionadas ao acervo já acumulado em anos anteriores, permitiu-nos investigar 13 espécies diferentes de copépodos, compreendendo ao todo 117 exemplares, pertencentes a 8 famílias e 11 gêneros. A maior parte dêsse material foi colecionada entre os anos de 1940 e 1948. Dez novos indivíduos, provenientes de São Sebastião (litoral norte do Estado de São Paulo), colhidos na data de 3 de novembro de 1949 e pertencentes ao gênero Caligus, não puderam ser classificados por falta de bibliografia.

Nos últimos quatro anos, examinamos grande número de espécimes marítimos, dos quais colecionamos diversos componentes dos Isopoda. Provàvelmente, o estudo dêsse acêrvo fará parte de futura publicação.

0 exame dêsse material oriundo de 22 exemplares marítimos, indicanos que a porcentagem de ecto-parasitismo não é elevada, desde que 12 dêles possuiam, apenas, 1 parasito, 5 abrigavam dois, achando-se os 5 restantes fortemente parasitados, apresentando, respectivamente, 10, 14, 16, 18 e 37 parasitos. O espécime mais atacado foi um Baiacú - Chilomycterus shoepfii (Walbaum), que contava 37 hóspedes diminutos, da espécie Tucca impressus.

Dos peixes parasitados, só tivemos ocasião de examinar a metade. O restante foi manipulado pelos próprios doadores que nos enviaram, apenas, os parasitos. Cêrca de $29 \%$ dos representantes ictiológicos que 
examinamos apresentava-se, portanto, absolutamente normal, sem qualquer indício de depauperamento orgânico.

\author{
Ordem Copepoda \\ Subordem Cyclopoida \\ Família Bomolochidae \\ Gênero Tucca Kröyer, 1837
}

1 - Tucca impressus Kröyer.

Sinonímia: Tucca impressus, Wilson 1911, vol. 39, p. 354, pls. 48-49;

Wilson 1932, Bull. 158, p. 379-380, fig. 234.

Ocorrência: 37 fêmeas fixadas ao corpo e às nadadeira de um Baiacú

- Chilomycterus schoepfii (Walbaum).

Proveniência: Praia Grande (Município de S. Vicente), Estado de S. Paulo. Oferta do Snr. José Cantinho Pereira. Data: 27-7-1944.

Distribuição: Indias Ocidentais, em Diodon hystrix (Kröyer); costa ocidental africana, em Diodon sp., (Herdman); Beaufort, em Chilomycterus sp., (Wilson); Woods Hole (Wilson).

Características:Segmento cefálico pequeno e hemisférico; abas laterais, divididas no centro em dois lóbulos; pescoço eurto, fazendo parte do segundo segmento; terceiro, quarto e quinto segmentos muito mais largos do que o segmento cefálico; terceiro e quarto par de pernas situados na face ventral do tronco; ausência do quinto par de pernas; segmento genital pequeno; ramo eaudal unido à superfície ventral do abdomen; porção posterior do tronco, tri-lobada; primeira antêna com 4 segmentos; antêna tri-segmentada. Sacos ovígeros de forma cilíndrica; grande quantidade de ovos, de pequeno diâmetro. Colorido branco acinzentado, eom tonalidades brilhantes.

Wilson (1932, p. 380) diz ser a presente espécie sempre encontrada sôbre as nadadeiras dos seus hospedeiros mas, dos 37 exemplares por nós examinados, grande número achava-se aderente às várias partes do corpo.

Tamanho: 1.52 a $1.8 \mathrm{~mm}$.

$$
\begin{gathered}
\text { Subordem Caligoida } \\
\text { Família Caligidae } \\
\text { Gênero Caligus Müller, } 1785 .
\end{gathered}
$$

2 - Caligus bonito Wilson.

Sinonímia: Caligus bonito, Wilson 1932, Bull. 158, p. 407-408, fig. 255 .

Ocorrência: 14 fêmeas aderentes às brânquias de um Bonito rajado

- Katsuwonus pelamis (L.,). 
Proveniência: Ilhas Alcatrazes (litoral norte do Estado de S. Paulo) em 12-9-1948, oferta do snr. Marcio de Campos Pimentel.

Distribuição : Costa ocidental africana (Brian); Woods Hole (Wilson).

Características: Cabeça fundida com os três primeiros segmentos toráxicos; carapaça medindo mais da metade do comprimento total, com largura igual à própria extensão; placas frontais providas de lúnulas ; quarto segmento mais largo do que o segmento genital, estreitando anteriormente; abdomen bi-segmentado, do tamanho do segmento genital; maxilípodo provido de garra forte. Colorido amarelo pálido transparente; olhos vermelhos brilhantes; face dorsal provida de manchas pardo escuras.

Tamanho: 5.3 a $5.5 \mathrm{~mm}$.

\section{3 - Caligus sp.}

Ocorrência: 16 fêmeas capturadas em 26-9-1949 e 10 outras obtidas em 3-11-1949, em duas Prejerébas - Lobotes surinamensis (Bloch), pescadas em espinhel.

Proveniência: Cananéia (litoral sul do Estado de S. Paulo).

Os exemplares obtidos em uma das excursões do Instituto Paulista de Oceanografia, no litoral sul do Estado de S. Paulo, não puderam ainda ser classificados por falta de bibliografia. Constituem caractéres essenciais dos exemplares Cefalotórax fortemente achatado, dorso-ventralmente, recoberto por carapaça que mede menos da quarta parte do comprimento total do corpo, um pouco mais alargado abaixo do centro, com área cefáliea ampla, circundada por outras áreas laterais mais compridas do que estreitas, terminando por exibir área toráxica mais estreita do que larga; placas frontais mais ou menos estreitas, separadas no centro por sinus muito estreito; olhos na linha mediana do corpo; segmento toráxico livre, pequeno; segmento genital piriforme, mais estreito na base; abdomem bi-segmentado, de formato cilíndrico, medindo, sem as lâminas caudais, mais do triplo do segmento genital; sacos ovígeros quase do comprimento do abdomen. Colorido branco opaco; sacos ovígeros de côr pardo escura.

Tamanho: 11.4 a $11.9 \mathrm{~mm}$.

\section{Família Euryphoridae}

Gênero Alebion Kröyer, 1863

\section{4 - Alebion fuscus Wilson.}

Sinonímia: Alebion fuscus, Wilson 1932, Bull. 158, p. 421-422, fig. 265 ; Carvalho 1940, p. 275-276, pl. 20, fig. 1-4.

Ocorrência: 2 fêmeas colhidas pelos snrs. H. Zellibor e I. Hauff, em junho de 1940, em cação de gênero não determinado.

Proveniência: Praia Grande (Município de S. Vicente), Estado de S. Paulo.

Distribuição: Menemsha Bight, Marthas Vineyard (Wilson). 
Características : Carapaça elíptica, mais comprida do que larga; placa frontal provida de sinus arredondada no ápice e mais alargada nas extremidades, cobrindo um têrço do artículo basal da antênula; abdômen bisegmentado, com o segmento basal muito largo; antêna robusta, dotada de gancho preensôr, com ponta virada para cima; maxilípodo possante, em forma de garra; ramo eaudal muito mais comprido do que largo. Colorido pardo, com irisações mais claras, partindo do centro para a periferia, mais carregado nas regiões um tanto espessas do corpo.

Tamanho: $9 \mathrm{~mm}$.

\section{Família Pandaridae}

Gênero Perissopus Steenstrup \& Lütken, 1861.

5 - Perissopus communis Rathbun.

Sinonímia: Perissopus communis, Rathbun 1887, vol. 10, p. 560 pl. 29-30; Wilson 1907, vol. 33, p. 354, pl. 17-18; Wilson 1932, Bull. 158, p. 425-426, fig. 267; Carvalho 1940, p. 277-280, pl. 21 , figs. 5 a 19.

Ocorrência: 18 fêmeas colhidas no cação Eulamia limbata (Müller \& Henle), no ano de 1936; e fêmeas, de idêntico hospedador, obtidas em maio de 1940.

Proveniência: Praia Grande (Município de S. Vicente), Estado de S. Paulo, oferta dos snrs. H. Zellibor e I. Hauff.

Distribuiẹão: Califórnia; Pensacola, Flórida; Golfo do México; Beaufort, Carolina do Norte; St. Marys River, Flórida (Atlântico); Woods Hole, Vineyard Sound (Rathbun, Wilson); Baía de Púlpito, lat. $24^{\circ} 41^{\prime} \mathrm{N}$. long. $14^{\circ} 51^{\prime}$ Oeste; costa do Marrocos francês (Stekhoven).

Características: Placa saliente e mais ou menos delimitada por uma estría nítida, na porção posterior; carapaça semi-elíptica, estreitada anteriormente e alargada nos ângulos posteriores; margens laterais ligeiramente convexas; placas do segundo segmento separadas uma da outra e de formato quase elíptico; placas dorsais do terceiro par, menores do que as do primeiro, de forma ligeiramente elíptica, quase unidas na linha mediana; segmento genital pouco maior do que o comprimento da earapaça, de forma arredondada na porção anterior e margens laterais convexas, sendo os cantos posteriores dessas margens munidos de agudas pontas salientes; entre essas duas saliências e na base do segmento genital, bem como no centro da linha mediana do corpo, existe um processo amplo, em forma de " $U$ " invertido; abdômen pequeno e arredondado, uni-articulado e fundido com o segmento genital. Colorido branco amarelado, sem qualquer pigmentação.

Tamanho: 3.8 a $4.3 \mathrm{~mm}$. 


\section{Gênero Pandarus Leach, 1816}

\section{6 - Pandarus smithii Rathbun.}

Sinonímia: Pandarus smithii Rathbun 1886, vol. 9, p. 315, pl. 5-7; Wilson 1908, vol. 33, p. 410-414, pl. 29-30; Wilson 1932, Bull. 158, p. 434-435; Carvalho 1940, p. 281-282.

Ocorrência: 1 fêmea capturada em 1936; 2 fêmeas obtidas em maio de 1940, ambas parasitando exemplares de cação Eulamia limbata (Müller \& Henle).

Proveniência: Praia Grande (Município de S. Vicente), Estado de S. Paulo, oferta dos snrs. H. Zellibor e I. Hauff.

Distribuição: Ilhas Hawai; Ilha Laysan, Oceano Pacífico; Golfo do México; Long Island; Vineyard Sound, Woods Hole (Wilson).

Características: Carapaça oval, mais larga do que comprida, com margens laterais posteriores formando lóbulos curtos, largos, com cantos arredondados; margem posterior entre os lóbulos, munida de processo dentado; placa frontal ampla e proeminente, mais larga nas extremidades, com a porção central côncava; órgãos visuais ocultos pela pigmentação escura da carapaça; segundo segmento toráxico com três jogos de placas dorsais: um par situado lateralmente, de forma oval ou elíptica, duas vêzes mais comprido do que largo e acentuadamente divergente; uma placa impar, semi-elíptica, no centro da linha mediana; um par, de forma quase circular, completamente separado na sua base, deixando um espaço amplo entre as margens internas, na direção do eixo do corpo; placas dorsais do quarto segmento muito largas, separadas por sinus, curto, triangular, aberto na porção posterior, sôbre o eixo do corpo e que cobrem as três partes de segmento genital; placas do sexto segmento piriformes, com margens laterais e posteriores arredondadas; abdômen pequeno; lâminas anais do comprimento do sexto segmento. Colorido amarelado, com uma grande mancha castanho escura ocupando quase tôda a carapaça; manchas da mesma côr, um tanto esmaecidas, no centro das placas dorsais; presença de desenho mais ou menos simétrico, em forma de álteres, na extremidade do segmento genital.

Tamanho: 8.8 a $9.5 \mathrm{~mm}$.

\section{7 - Pandarus sinuatus Say.}

Sinonímia: Pandarus sinuatus Rathun 1886, vol. 9, p. 310, pl. 5:7; Wilson 1907, vol. 33, p. 417, pl. 32-33; Wilson 1932, Bull. 158, p. 437, fig. 275; Carvalho 1940, p. 283-284, pl. 23, fig. 37-42.

Ocorrência: 2 fêmeas capturadas em 1936; 1 fêmea obtida em junho de 1940, ambas sôbre cações da espécie Eulamia limbata (Müller \& Henle.

Proveniência: Praia Grande (Município de S. Vicente), Estado de S. Paulo, oferta dos snrs. H. Zellibor e I. Hauff. 
Características: Carapaça semi-elíptica, mais larga posteriormente, com lóbulos eurtos, arqueados e pontas quase agudas; linha da porção posterior da cabeça quase sinuosa, chegando a dar a impressão de ser serrilhada; placa frontal larga, um tanto proeminente, cujas extremidades cobrem $2 / 3$ do segmento basal da antênula; placas dorsais do segundo segmento, de forma elíptica ou levemente ovalada, divergente e muito separadas; placa mediana, impar, mais ou menos larga, curta e provida de margens lisas; placas do terceiro segmento de forma circular, tamanho pequeno, separadas na face interna basal por um sinus mediano amplo; placas do quarto segmento, muito largas, atingindo e até ultrapassando o limite do segmento genital, com sinus mediano amplo; segmento genital de forma elíptica, com cantos arredondados, 1/5 mais comprido do que largo e mais estreito posteriormente; sexto segmento com placa quase arredondada, mais larga do que comprida, estreitada anteriormente, formando uma ligeira depressão na porȩão média posterior ; ramo caudal divergente, com extremidades agudas, de comprimento idêntico ou um tanto mais longo do que a placa do sexto segmento. Colorido creme, com uma grande mancha acastanhada, escura, cobrindo quase tôda a superfície dorsal da carapaça, exceção feita à região onde se encontram os órgãos visuais; manchas da mesma côr, mas de tonalidade menos carregada, sôbre as placas dorsais do segundo, terceiro e quarto segmentos.

Tamanho: $8 \mathrm{~mm}$.

8 - Pandarus marcusi Carvalho.

Sinonímia: Pandarus marcusi Carvalho 1940, p. 284-287, pl. 24, figs. 43-51.

Ocorrência: 1 fêmea capturada em 1940, parasitando o eação Eulamia limbata (Müller \& Henle).

Proveniência: Praia Grande (Município de S. Vicente), Estado de S. Paulo, oferta dos Snrs. H. Zellibor e I. Hauff.

Distribuição: Até o presente, conhecida sòmente da Praia Grande.

Características: Carapaça oval, anteriormente estreitada e alargada na direção posterior, margens laterais convexas a partir do têrço inferior onde os lóbulos são curtos, ligeiramente arredondados e convergentes; margem posterior que separa os lóbulos laterais recurvada sôbre a placa semi-elíptica mediana dorsal do segundo segmento e recortada em pontas curtas e arredondadas que não chegam a apresentar o aspecto de dentes; placa frontal larga e proeminente, com a porção central mais estreita e côncava, com extremidades mais amplas e pontas arredondadas, cobrindo quase que totalmente o segmento basal da antênula; carapaça fortemente marcada por pigmento bruno escuro, quase negro, que não atinge o limite das margens laterais, deixando dois amplos claros em direção aos lóbulos laterais posteriores; a parte central dessa mancha escura possue desenho em campo elaro, em forma de " $T$ " irregular; placa do quarto segmento muito alargada; segmento genital elipsóide; sexto segmento com base 
truncada, e ponta nas margens laterais inferiores; região abdominal pequena, atingindo quase o centro da placa que forma o sexto segmento.

Tamanho: $9 \mathrm{~mm}$.

Família Pseudocycnidae

Gênero Pseudocycnus Heller, 1865

9 - Pseudocycnus appendiculatus Heller.

Sinonímia: Pseudocycnus appendiculatus, Wilson 1932, Bull. 158, p. 474-475, fig. 285; Carvalho 1950, p. 99-102.

Ocorrência: 6 fêmeas capturadas, em abril de 1949, nas brânquias de 6 Bonitos Gymnosarda alleterata (Rafinesque).

Proveniência: S. Sebastião (Litoral norte do Estado de S. Paulo), material colecionado pelos snrs. Profs. W. Besnard e Waldomiro B. Borodin.

Distribuição: Oceano Atlântico (Heller); Mediterrâneo (Richiardi, Carus); Atlântico Norte, na altura da Espanha (Brian); Aden (Basset-Smith); Ilhas Loyalty (Stebbing); S. Sebastião, Estado de S. Paulo, Brasil. (Carvalho).

Características: Cabeça fundida com o primeiro segmento; segundo e terceiro segmento livres; quarto e quinto segmentos fundidos com o segmento genital, formando corpo cilíndrico, várias vêzes mais longo do que largo; carapaça ovalada, estreitada anteriormente; segundo e terceiro segmentos ligeiramente mais largos do que a carapaça, cada um provido de placas dorsais rudimentares; quarto e quinto segmentos unidos ao segmento genital, formando troneo teretiforme, cêrea de seis vêzes mais longo do que largo; abdômen uni-segmentado; ramo eaudal lanceolado e divergente. Colorido creme; havendo acúmulo de sangue no tubo digestivo, exibem côr avermelhada brilhante; ovisacos pardo escuros.

Tamanho: 14.8 a $15.9 \mathrm{~mm}$.

F'amília Lernaeidae

Gênero Lernaeenicus Le Sueur, 1824

10 - Lernaeenicus longiventris Wilson.

Sinonímia: Lernaeenicus longiventris, Wilson 1932, Bull. 158, p. 483484, fig. 290.

Ocorrência: 2 fêmeas retiradas da carne de uma Sororóca Scomberomorus maculatus (Mitchill), capturada em setembro de 1943.

Proveniência: Santos.

Distribuição: Oceano Atlântico, a suleste de Nantucket; Norfolk; Beaufort, Carolina do Norte (Wilson). 
Características: Cabeça fundida com o tórax e provida de 3 expansões cilíndricas ou nódulos curtos, um em posição posterior e dois laterais; pescoço muito extenso, bem mais comprido do que o tronco que é cilíndrico; porȩão abdominal filiforme, medindo a metade do comprimento do pescoço e cêrea de trinta vêzes mais longo do que largo; os dois primeiros pares de pernas são bi-ramosos; terceiro e quarto pares uni-ramosos; sacos ovígeros medindo de 10 a $15 \mathrm{~mm}$. Colorido ereme; ovidutos pardos; sacos ovígeros pardo escuros.

Tamanho: $30 \mathrm{~mm}$ (total); sacos ovígeros de $14 \mathrm{~mm}$ de comprimento.

Família Pennelidae

Gênero Pennella Oken, 1816

11 - Pennella filosa (L.,).

Sinonímia : Pennella filosa, Wilson 1932, Bull. 158, p. 490-491, fig. 295.

Ocorrência: 1 fêmea capturada em Peixe-lua - Mola mola (L.,), em 12 de novembro de 1944.

Proveniência: Santos (exemplar peseado em S. Sebastião).

Distribuição: Mediterrâneo (Lineu, Ellis, Cuvier, Leight-Sharpe) ; Ilhas Britânicas (Norman, T. e A. Scott); costa atlântica de Nova Jersey (Leidy, Fowler); Atlântico Norte (Brian) ; Vineyard Sound (M. T. Thompson, Rathbun) ; Nova Escocia (Wilson) ; Marthas Vineyard (Wilson).

Características: Cabeça mais larga do que comprida, fundida com o primeiro segmento, um tanto globular, em geral ligeiramente achatada dorso-ventralmente; presença de processos túmidos na região posterior da cabeça; pescoço comprido, exibindo o mesmo diâmetro em tôda a sua extensão; tronco com o dôbro do diâmetro do pescoço; abdômen alongado, provido de anéis, com apêndices plumosos ramificados nos flancos, próximos à superfície ventral; sacos ovígeros medindo pouco mais do dobro do comprimento do corpo. Colorido amarelo dourado; sacos ovígeros amareloalaranjado escuro.

Tamanho: $186 \mathrm{~mm}$, sem os sacos ovígeros.

Subordem Lernaeopodoida
Família Chondracanthidae
Gênero Blias Kröyer, 1863

12 - Blias prionoti Kröyer.

Sinonímia: Blias prionoti, Wilson 1932, Bull. 158, p. 493-494, fig. 296a.

Ocorrência: 1 fêmea capturada nas brânquias de uma Cabrinha Prionotus sp., (espécie muito próxima de P. beanii (Goode), em 7 de agôsto de 1947. 
Proveniência: Santos (Mercado Municipal), doação do snr. Vicente Molinari.

Distribuição: Costa do Brasil (Kröyer); Woods Hole (Wilson).

Características: Cabeça esférica, separada do tronco por uma chanfradura horizontal acentuada, medindo cêrea de $1 / 3$ do comprimento do tronco; antena tri-segmentada; segunda antena bi-segmentada, sendo o segmento distal munido de gancho apical forte; abdômen bi-segmentado; no segundo segmento figura o ramo caudal, um pouco maior do que o segmento anal, curvado à moda de parêntesis. Colorido pardo amarelado uniforme.

Tamanho: $1.98 \mathrm{~mm}$ (faltavam os sacos ovígeros).

\section{3 - Chondracanthus merluccii (Halten).}

Sinonímia: Chontracanthus merluccii, Wilson 1932, Bull. 158, p. 498500, fig. 298.

Ceorrência: 1 fêmea capturada nas brânquias de uma Pescadinha do Reino - Merluccius hubbsi Marini, capturada em 17 de dezembro de 1947.

Proveniência: Ubatuba (litoral norte do Estado de S. Paulo).

Distribuição: Mares britânicos (T. e A. Scott); Mar do Norte (Timm); Mediterrâneo (Heller, Valle, Carus, Brian; Atlântico Norte (Goode); Woods Hole (Rathbun, Wilson); Baía de Caseo, Washington (Wilson).

Características: Cabeça pequena, trapezoidal, separada do tórax por constrição mais ou menos definida, mais larga na porção posterior do que na anterior, meia vez mais longa do que larga e a margem frontal um tanto arredondada; earapaça dividida, no dorso, por linha longitudinal bem evidente; primeiro e segundo segmentos livres, mais estreitos do que a cabeça, de onde partem as pernas nadadoras; segundo segmento muito mais largo do que o primeiro; últimos três segmentos fundidos, exibindo chanfradura evidente na porção central; linha mediana da superfície ventral, em face do segmento genital, provida de pequeno carúnculo; segmento genital delgado, um tanto achatado e divido transversalmente por fenda transversa. Colorido branco opaco.

Tamanho: $11.8 \mathrm{~mm}$ (total); sacos ovígeros $13.9 \mathrm{~mm}$.

\section{SUMÁRIO}

A presente nota trata de alguns copépodos, parasitos de peixes marítimos, e baseia-se em uma coleção de ecto-parasitos pertencentes às Subordens Cyclopoida, Caligoida e Lernaeopodoida que se eneontra no Instituto Paulista de Oceanografia e que foi acumulada entre os anos de 1940 e 1949. Uma parte dos espécimes aqui tratados foi obtida por 
doação; outra teve por origem as periódicas viagens de estudo efetuadas pelos funcionários do Instituto, ao longo do litoral do Estado de S. Paulo; finalmente, uma pequena parte devida à aquisição de exemplares parasitados, nas feiras e mercados de Santos e S. Paulo.

Dessa maneira, conseguiu o autor manipular 117 espécimes pertencentes a 8 famílias, 11 gêneros e 13 espécies diferentes, uma das quais, do gênero Caligus, não pôde ser determinada, por falta de bibliografia.

O material foi retirado de 22 espécimes marinhos, entre os quais figuraram apenas 5 fortemente parasitados, contendo $10,14,16,18$ e 37 hóspedes. Nenhum dos hóspedes, porém, apresentou qualquer indício de depauperamento orgânico evidente.

\section{SUMARY}

The present note represents the inventary of the parasitic copepods found on marine fishes between 1940-1949 and which are kept in the "Instituto Paulista de Oceanografia" (São Paulo Oceanographic Institute). They all belong to the Suborders Cyclopoida, Caligoida and Lernaeopodoida and were partly received as donations and partly collected by the staff of the Institute, during its periodic trips to the coast of the State of São Paulo (Brazil); finally, a small fraction was obtained from parasitized fishes purchased on the markets of Santos an São Paulo.

The author, thus, gathered 117 specimens, distributed by 8 families, 11 genera and 13 different species, one of which belongs to the genus Caligus and could not be specifically determined due to the lack of bibliography.

The Copepods were obtained from 22 fishes, among which only 5 were abundantly infected and exhibited respectively $10,14,16,18$, and 37 parasites.

None of the hosts showed any sign of evident organic weakness.

\section{BIBLIOGRAFIA}

CARVAlHO, J. de P., 1940 - Notas sôbre alguns Caligoida, com a descrição de Pandarus marcusi sp. nov. Bol. Fae. Fil. Ci. e Letras Univ. S. Paulo, vol. 19. Zoologia n. ${ }^{\circ}$, p. 271-302, pl. 20-24, fig. 1-2 no texto. S. Paulo.

RATHBUN, R., 1886 - Deseriptions of parasitic copepods beloging to the genera Pandarus and Chondracanthus. Proc. U. S. Nat. Mus. vol. 9, p. 310-324, pl. 1-7. Washington.

RATHBUN, R., 1887 - Deseription of new species of parasitie Copepods, belonging to the genera Trebius, Perissopus and Lernantropus. Proc. U. S. Nat. Mus., vol. 10, p. p. 559-571, pl. 1-7. Washington.

WILSON, C. B., 1907 - North American parasitic Copepods belonging to the family Caligidae. Parts 3 and 4. A revision of the Pandarinae and the Cecropinae Proe. U. S. Nat. Mus., vol. 33, p. 323-490, pl. 17-43. Washington.

WILSON, C. B., 1911 - North American parasitic Copepods belonging to the family Ergasilidae. Pro. U. S. Nat. Mus., vol. 39, p. 263-40, pl. 41-60, figs. 1-41. Washington.

WILSON, C. B., 1932 - The Copepods of the Woods Hole region Massachusetts. Bull. 158, U. S. Nat. Mus., XIX +635 , pl. 1-41. Washington. 